\begin{tabular}{|ccc}
\hline Sournals & $\begin{array}{c}\text { INTERNATIONAL JOURNAL OF } \\
\text { ORGANIZATIONAL LEADERSHIP }\end{array}$ & $\begin{array}{c}\text { INDUSTRIAL } \\
\text { MANAGEMENT } \\
\text { INSTITUTE }\end{array}$ \\
\hline \hline
\end{tabular}

\title{
Talent management: The great challenge of leading organizations
}

\author{
Vajiheh Saadat $^{1 *}$, Zahra Eskandari ${ }^{2}$ \\ ${ }^{1}$ M.S. in Public Management, Central Tehran Branch, Islamic Azad University, Tehran, Iran \\ ${ }^{2}$ M.A. Student of Business Management, University of Tehran, Tehran, Iran
}

\begin{abstract}
Keywords:

Organization, Talent, Talent Management

Received

18 November 2015

Received in revised form 10 April 2016

Accepted

16 April 2016

Correspondence:

va.saadat15@yahoo.com

Today is called as the age of increasing competition among the organizations against the limited resources. Nowadays, organizations reached higher consciousness that talented human resources are valuable resources and if they can be managed strategically, they will be associated with maximum return on investment. It is obvious that getting benefits from talented human resources requires proper management and this is one of the major challenges for organizations. Talent management as a system of identification, recruitment, training, promotion, and retention of talented people has been proposed with the aim of optimizing the organization and to achieve business results. In other words, talent management refers to the systematic and dynamic process that by which human resources are being identified to fill key jobs and positions in the future and they get ready through a wide variety of educational and training programs for these occupations. With respect to the use of talent management at all levels of the organizations to release the true potential of existing human resources and orient and direct their talents to achieve the expected outcomes, this study aims to review the literature related to the concept of talent management and related topics to establish gaps for further studies on the topic.
\end{abstract}

(C)AIMI Journals

\section{Introduction}

The most important concern of developing the human resource managers, on the eve of the $21^{\text {st }}$ century, is the maintenance and growing the core management capabilities and talents. It has become an increasingly integral part of strategy and the perspective of leading organizations. Today, organizations fully recognized that it is required the best talents to succeed in the world of complex economy and persist in business environment. Parallel to the understanding the importance of the recruitment, development, and maintenance of talents the organizations have 
realized that the talents are the critical resources that need management for getting the best results (Tajuddin \& Maali, 2008). There are some factors which are derived from surveying the circulation of people in the organizations and they should be considered into account such as how they enter to the organization, develop their skills, and move to the high levels of their organizations or out of them. The talent management is not only attracting and maintaining the best people but also is identifying and removing improper people (Ulrich, 2008; Ulrich \& Brockbank, 2009).

On the other hand, the talent management guarantees that personnel circulate properly in existing jobs in organizations and therefore correct people are elected for right job at the correct time (Kesler, 2002). So, it is not unreasonable that the talent management is considered as a super leverage to achieve success and organizational reputation.

\section{The Concept of Talent Management}

CIPD-centered institute stated that talent consists of complex components including skills, knowledge, cognitive abilities, and high potential. Talent management also seeks to focus on high potential of human resources (Guy \& Doris, 2009).

Talent management involves recognizing various approaches which provide a complex to create a coherent whole. It is a tool for developing and implementing some coordinated activities that organizations need them to attain and maintain the talented human resources (Armstrong, 2006). Lewis and Hackman (2006) introduced the three basic streams of talent management in the field of human resource management. In the first stream, talent management is defined as a complex of the human resource tasks like recruitment, selection, education, and development. From this point of view, these types of tasks noted that the talent management may be beyond the daily word or human resource euphemism. Moreover, they imply that the talent management is a systematic method for implementing the tasks of human resource management, accurate performing, and using the advanced tools like internet and related software with the aim of implementing at all levels and parts of the organization.

The second stream of talent management based on Lewis and Hackman's model focuses on predicting or modeling the human resource processes in the organization based on factors such as skills for the future workforce, supply and demand, and erosion of the labor. From this perspective, the talent management is synonymous with human resource or workforce planning.

The third stream emphasized on evaluating talented people in terms of their performance and potential. People with high potential are noticeable during the use of workforce in the organization and the organization tries more to attract them (Guy \& Doris, 2009). Generally, talent management is considered as a cautious attitude for using the elite's talent and competence in order to fulfill the basic needs and general or partial aims of organization.

\section{The Importance and Necessity of Talent Management}

Today, human resources development managers are faced with serious questions such as how human resource development field can be active and make focus on advancing the organization strategies? How can attract and retain the best talents in organization (Cartwright, 2008). The answers of such questions are found in a strategic concept with the name of talent management. 
Also, economic globalization and demographic changes of the workforce has doubled the need of talent management studies in field of organization and management. A talented person has a complex of knowledge, skill, capability, and the required commitment for achieving the organizational goals (Ulrich, 2008).

Also, better talents are resource of producing the added value and empowerment of applying the new technologies and innovation will result in better business performance. While the current research shows that most of big organizations are faced with the lack of talented people. Sparrow and Hiltrop (1994) surveyed the increasing problems in terms of the lack of talents in most of the European countries and concluded that in the $21^{\text {st }}$ century, there is need for individuals with expansive necessary skills and abilities to encounter with unpredictable companies' needs (Hiltrop, 1999). Considering the major effects of such kind of strategic resource and lack of it, every day strategic talent management has become more important. Generally, the common reasons for talent fulfillment and maintenance includes knowledging economy, sever competition, displacement, and personnel transport.

\section{Goals of Talent Management}

Generally, the main goals of talent management include realizing the development posts and management capability gaps, maintaining of key technicians, recognizing the risky managerial empty positions, describing the strategic program of organization through listing its needs, capabilities, and human skills, defining and determining the existing situation of organization in terms of its capabilities, skills, and finding its lacks and needs.

There are also some secondary talent management goals such as measurement and continued control of existing capabilities and its distance from optimal capabilities and skills through strategies and educational programs, recognizing, developing, and keeping the highpotential personnel, reinforcing the stakeholders and understanding the consumers, reducing the costs of external workforce, and challenges dealing with the managerial development path (Sayyadi, Mohammadi, \& Nikpour, 2011).

\section{History of Talent Management Approach}

Management of organizational talents in human resource management field is not a new concept. Tulgan (1996) stated that the talents of generation X (people who were born in the years after the Second World War) and their trends for recruiting activities result in revolution in these activities. Such kind of revolution is talent-based. In such condition, the concept of the permanent recruitment in an organization is removing rapidly (Cartwright, 2008)

In 1997, the term "war for talent" was introduced for the first time by Mckinsey Consultant Company. In Mckinsey Global survey results, it was seen that organizations which are more successful in attraction, development, and maintenance of talented managers have more benefits. It leads to the change of attitude towards the talented people in organizations and they regard as a basic source for creating the competitive advantage (Guy \& Doris, 2009).

In the 1960s and 1970s, talent management as a marginal responsibility had assigned to the personnel department while now it is considered as an organizational task which its responsibility is on all of the departments (Maali Tafti \& Tajuddin, 2008). Therefore, most of organizations based on the determined frameworks try permanently to study and survey the 
talents, recognize the current and future posts, and assign the suitable and enough time to bridge current and future needed talents.

Organization leaders' awareness of the fact that the talents and abilities of the personnel are key factors for achieving the success in business helps the maintenance of their high-potential personnel. Generally, the talent management is considered as the last wave in the field of human resource management (Guy \& Doris, 2009). Organizational scholars and management analysts believe that nowadays in the business field, the management of human resource development no longer regards as the only center for costing within competitive environment. Due to the personnel and educational diversity, the organizations try to add value to its property in order to capture the expected benefits and make the costs less (Cartwright, 2008).

Talent management is not necessarily part of human resource management. Moreover, the results implied that both of talent management and human resource management focus on the integration of business strategies and selection of right people for the jobs.

Also, human resource management is more expansive than talent management. Their difference is that human resources rely heavily on task while talent management on people.

Talent management relates to all aspects of human resource development process and is used for growth and development of all personnel. Recognition and selection of some people are considered as separate processes to reach the aims or goals such as displacement (Maali Tafti \& Tajuddin, 2008).

Organizational culture has a major role in the attraction and maintenance of key talents. So, establishment and development of organizational culture to provide the suitable position for talent management creation and implementation are necessary in order to have effective talent management.

On the other hand, focusing on the implementation of talent management approach in organization affects on components of organizational culture. Through the talent management, employees would be attracted to the organizations. Morton (2005) also believed that the talent management is necessary for personnel to involve in an organization.

Talent management process components consist of aligning talent management with their business strategy, recognizing and developing the existing talents in organization, evaluating the readiness of employees' talents for taking new job opportunities, and accelerating the talent development (Cartwright, 2008).

\section{Armstrong's Talent Management Model}

One of the models which describe the different dimensions of talent management is Armstrong's model (2006). In this model, the talent management process begins with business strategy as a path map. Through maintenance and management of talents in inside or outside of organization, the organizations try to prevent talented personnel from leaving the organization. Such kinds of organizations are the source of skilled, committed, and engaged workforces (Armstrong, 2006). Generally, the elements of this model include the related activities to attract the talents, deployment and maintenance of talents, and development of them. 


\section{Optimizing Talent Management Process in Organizations}

There are some principals to implement talent management in the organizations that observance of them is necessary in each field. Implementation of talent management program in organization needs an effective performance measurement system. Through applying such kind of system, the talented personnel with high capability and hidden or unhidden competences should be identified and introduced. The organization also should have an efficient and reasonable relation system that through following and applying this system each person can climb the career ladder.

With regard to the employees' competence and performance and managers' coach approach as an important principal in talent management, the talented personnel of organizations can find their solutions, improve their skills, correct and change their behaviors, change their attitudes, and achieve their the treasures of wisdom and tact (Cartwright, 2008).

Also, some elements realize the implementation of talent management process such as organization program, employment policies, development program, maintenance program, program evaluation, and withdrawal program.

\section{Positive Outcomes of Talent Management}

Talent management guarantees that suitable people with suitable skills are placed in suitable place and in appropriate activities have been associated to it. Also, their career acts as an inciting factor to make better job situations in organization and out of it. Talent management provides the proper processes and tools to support and empower the managers. Therefore, what should be expected from the personnel improve the work relationships. The organizations that invest in talent management earn the high rates of return on its investments and therefore there are various kinds of talents in the organization. In this condition, organization would benefit from healthy and motivated workforce which helps to establish organizational productivity (Maali Tafti\& Tajuddin, 2008). Also, self-esteem and motivation for improving higher performance results from applying talent management strategy in organizations (BethkeLangenegger, Mahler, \& Staffelbach, 2010, 2011).

\section{Challenges Facing Talent Management}

The valuable talents are very rare and their importance is increasing every day. Factors such as retirement and exit of empowered personnel from work environment, new needed skills to reach the optimal future, and rapid changes of person's lifestyle also add importance to it (Serrat, 2010).The personnel's expectations are changing and adapting frequently. Nowadays, the personnel of organizations focus on management and leadership methods more than any other thing. They increasingly tend to perform their best, display loyalty to their expertise and career more than organization, have less tolerance towards the structures, consider the importance of work-life balance, get ready to support the private entrepreneurship, and change the demographic situation of workforce. Apart from the organizational talents who approach to their retirement age, the young talents may not have approached to their appropriate threshold level of capabilities to replace them yet.

Having wrong perspective and attitude towards the talent management among personnel and managers makes some problems to achieve the goals. One of wrong perspectives regards to the 
talent management is that talent management should be considered as an independent process from other human resource development processes. Sometimes, it is assumed that talent management is only related to the key people in organization. Each person in the organization has a talent; however, some have more and some have less. Therefore, talent management processes should not be confined to a few people and executive roles (Armstrong, 2006). One of the talent management challenges in national level is increasing high rate of emigration and exit of talents employees or personnel from organizations.

\section{Strategies for Effective Talent Management}

For having effective talent management, the quantitative and qualitative need for the organization to talents should be determined according to their business goals and strategies (Cartwright, 2008). The key concepts and elements of having an effective talent management include a clear understanding of the organizations 'current and future business strategies, defining the key gaps between current and desired situation in terms of the required talents, designing a sound comprehensive plan for talent management to remove or close the key gaps. This program should be integrated into the business strategies and employment to make proper decisions for promoting of personnel decisions. There is a meaningful connection between the personal and organizational goals to clarify the exceptions and give the suitable feedback to manage the performance. Moreover, the development of the organizational talents to enhance and optimize the performance in current situation and readiness to transit to the optimal situation and focus on the talent strategy to succeed the organization, effective productivity measurement of personnel during and after the activities, and existence of relationship between talent management strategies in organization and national business strategies are other required elements. The way of talent management and development in relation with environmental or existing business strategies should be considered as an integral part of effective national business strategies (Mobini Dehkordi \& Tahmasb Kazemi, 2013). Furthermore, an especial attention should be paid to implement of talent management, accurate planning, strategic attitudes, goals, practical program, flexibility and dynamism of talent management system, establishment and development of organizational culture for creation and implementation of talent management, and comprehensive financial and moral support of organizational top manager's in implementation of talent management.

\section{Conclusion}

The organizations move through individuals and their talents have a main role in success of their organizations. So, the talent management is considered as an important part of management (Michaels, Handfield-Jones, \& Axelrod, 2001). The talent management is the process which looks to the future in addition to present and identifies the required people for present and future and tries to grow them and systematically remove the gaps between the current human resource in organization and required talents for leadership to answer to the future challenges (Wellins, Smith, \& Rogers, 2006).

Nowadays, the managers of the leading organizations well recognized that smart and talented personnel are the lead players in order to continue the offering their suitable products or services to consumers, avoid from their past mistakes and failures, and achieve competitive 
advantage. Therefore, the need for the approach that focuses on human resource practices and talent management to survive the organization is unavoidable especially in the third millennium with emphasize on competition and the complex economic fields.

\section{References}

Armstrong, M. (2006). A handbook of human resource management practices (10 ${ }^{\text {th }}$ ed.). London: Kong Page Business.

Bethke- Langenegger, P., Mahler, P., \& Staffelbach, B. (2010). Effectiveness of talent management strategies in Swiss companies. Lehrstuhl Human Resource Management, 16, 4-8.

Bethke-Langenegger, P., Mahler, P., \& Staffelbach, B. (2011). Effectiveness of talent management strategies. European Journal of International Management, 5(5), 5524-5539.

Cartwright, R. (2008). The talent management: New views to human capital development (A.M. Gudarzi, \& S. J. Hossieni, Trans.). Tehran: Rasa Institute of Cultural Services.

Guy, M., \& Doris, S. (2009). Future talent development: Talent management and succession planning practical guide to Husbandry ( $1^{\text {st }}$ ed.) (N, Jazani, Trans.).Tehran: Saramad Publication.

Hiltrop, J. M. (1999). The quest for the best: Human resource practices to attract and retain talent. European Management Journal, 17(4), 422-430.

Kesler, G. C. (2002).Why the leadership bench never gets deeper: Ten insights about executive talent development. Human Resource Planning, 25(1), 32-44.

Lewis, R. E., \& Heckman, R. J. (2006). Talent management: A critical review. Human Resource Management Review, 16, $139-154$.

Maali Tafti, M., \& Tajuddin, M. (2008). Attracting talents in a competitive market. Tadbir, 19(198), 74-75.

Michaels, E., Handfield-Jones, H., \& Axelrod, B. (2001). The war for talent. Boston, MA: Harvard Business School Press.

Mobini Dehkordi, A., \& Tahmasb Kazemi, B. (2013). The talents strategic management: An analysis of approaches, problems, and features. Strategy for Culture, 22, 105-134.

Morton, L. (2005). Talent management value imperatives: Strategies for execution. New York: The Conference Board.

Serrat, O. (2010). A primer on talent management. Washington, DC: Asian Development Bank Sparrow, P. R., \& Hiltrop, J. M. (1994). European human resource management in transition. London: Prentice Hall.

Sayyadi, S., Mohammadi, M., \& Nikpour, A. (2011). Talent management as a key concept in organizational domain. Monthly of Work \& Society, 135, 81-86.

Tajuddin, M., \& Maali, T. M. (2008). Why talent management? Tadbir, 191, 62-63.

Tulgan, B. (1996). Managing generation X: How to bring out the best in young talent. Oxford: Capstone Publishing.

Ulrich, D. (2008). The talent trifecta. Development \& Learning in Organization, 22(2), 32-35.

Ulrich, D., \& Brockbank, W. (2009). The HR business-partner model: Past learning and future challenges. People \& Strategy, 32(2), 5-7.

Wellins, S., Smith, B., \& Rogers, W. (2006). Talent management. Pittsburgh, PA: Development Dimensions International Press. 